\title{
Quantitative Microbial Risk Assessment of Drinking Water Quality to Predict the Risk of Waterborne Diseases in Primary-School Children
}

\author{
Jamil Ahmed ${ }^{1,2, *}$, Li Ping Wong ${ }^{1, * \mathbb{D}}$, Yan Piaw Chua ${ }^{3}$, Najeebullah Channa ${ }^{2}$, \\ Rasool Bux Mahar ${ }^{2}$, Aneela Yasmin ${ }^{4}$, James A. VanDerslice ${ }^{5}$ and Joshua V. Garn ${ }^{6}$ \\ 1 Centre for Epidemiology and Evidence-Based Practice, Department of Social and Preventive Medicine, \\ Faculty of Medicine, University of Malaya, Kuala Lumpur 50603, Malaysia \\ 2 US- Pakistan Center for Advanced Studies in Water, Mehran University of Engineering \& Technology, \\ Jamhsoro 76062, Pakistan; najeebchanna@outlook.com (N.C.); rb.mahar@faculty.muet.edu.pk (R.B.M.) \\ 3 Institute of Educational Leadership, Level 11, Wisma R \& D, UM, University of Malaya, Jalan Pantai Baru, \\ Kuala Lumpur 59000, Malaysia; chuayp@um.edu.my \\ 4 Department of Biotechnology, Sindh Agriculture University, Tandojam 70060, Sindh, Pakistan; \\ aneelayasmin@yahoo.com \\ 5 Department of Family and Preventive Medicine, University of Utah, Salt Lake City, UT 84112, USA; \\ jim.vanderslice@utah.edu \\ 6 School of Community Health Sciences, University of Nevada, Reno, NV 89557, USA; jgarn@unr.edu \\ * Correspondence: jamilahmed.uspcasw@faculty.muet.edu.pk (J.A.); wonglp@ummc.edu.my (L.P.W.)
}

Received: 25 March 2020; Accepted: 13 April 2020; Published: 17 April 2020

\begin{abstract}
Primary-school children in low- and middle-income countries are often deprived of microbiologically safe water and sanitation, often resulting in a high prevalence of gastrointestinal diseases and poor school performance. We used Quantitative Microbial Risk Assessment (QMRA) to predict the probability of infection in schoolchildren due to consumption of unsafe school water. A multistage random-sampling technique was used to randomly select 425 primary schools from ten districts of Sindh, Pakistan, to produce a representative sample of the province. We characterized water supplies in selected schools. Microbiological testing of water resulted in inputs for the QMRA model, to estimate the risks of infections to schoolchildren. Groundwater (62\%) and surface water $(38 \%)$ were identified as two major sources of drinking water in the selected schools, presenting varying degrees of health risks. Around half of the drinking-water samples were contaminated with Escherichia coli (49\%), Shigella spp. (63\%), Salmonella spp. (53\%), and Vibrio cholerae (49\%). Southern Sindh was found to have the highest risk of infection and illness from Campylobacter and Rotavirus. Central and Northern Sindh had a comparatively lower risk of waterborne diseases. Schoolchildren of Karachi were estimated to have the highest probability of illness per year, due to Campylobacter $(70 \%)$ and Rotavirus (22.6\%). Pearson correlation was run to assess the relationship between selected pathogens. V. cholerae was correlated with Salmonella spp., Campylobacter, Rotavirus, and Salmonella spp. Overall, the risk of illness due to the bacterial infection (E. coli, Salmonella spp., V. cholerae, Shigella, and Campylobacter) was high. There is a dire need for management plans in the schools of Sindh, to halt the progression of waterborne diseases in school-going children.
\end{abstract}

Keywords: QMRA; water quality; pathogens; health-risk assessment; primary-school children

\section{Introduction}

The United Nations has estimated that at least 2.5 billion people in low- and middle-income countries lack access to improved sanitation, and over 884 million lack access to improved drinking 
water [1]. As a result, an estimated 2.3 billion people across the world are suffering from water-related diseases [2]. Consumption of pathogenic microorganisms in drinking water may pose serious health risks due to waterborne diseases [3,4]. Drinking water is considered one of the important reservoirs of microbes in developing countries. Four Billion cases of diarrhea are reported each year, of which 2.2 million result in death, and children under five years are the main victims. Furthermore, more than $90 \%$ of the disease burden is contributed by the developing world [5,6]. Each bout of diarrhea progressively compromises the immune system, indirectly killing many more millions each year [7].

In Pakistan, rapid population growth, industrialization, and urbanization have stressed the water resources and compromised water quality, which subsequently negatively impacts children's school performance [8-10]. A recent study revealed that 21 million people in Pakistan are deprived of basic access to safe water [11]. Furthermore, Pakistan is among the top ten countries in the world with the lowest access to clean and safe water close to the home [11]. Water from unprotected springs and wells add to the high morbidity and mortality rate in Pakistan [12]. Main water sources are often contaminated with various pathogenic bacteria and hazardous chemicals, coming from the untreated discharge of influents into water bodies [13]. Waterborne diseases due to unimproved water include diarrhea, typhoid, dysentery, cholera, and Hepatitis A, which are leading causes of morbidity and mortality among children in Pakistan [12,14,15].

One of the serious impacts of diarrheal morbidity among children is the loss of school time due to illness. One study estimated that 670,000 Pakistani children miss school on average per day, due to water-related diseases [10]. Pakistani schools often have inadequate access to and use of water facilities. According to Sindh Education Management Information System (SEMIS), most of the primary schools of Sindh, Pakistan, do not have a safe drinking-water source, and the majority of schools are in need of clean drinking-water systems $[9,10]$. Schools often lack water-storage capacity; therefore, they must use alternate water sources, such as private venders, local wells, and reservoirs (springs and rainwater storage points). Local vendors are often unregistered, with no checks on them by authorities, and unhygienic handling of these sources may lead to contamination [15]. One local study in schools showed that only $25 \%$ of schools had onsite treatment facilities (mainly UV light) [8]. In another study in Pakistan, only one out of 14 water-filtration plants were meeting national water-quality standards. Both of these studies recommended periodic water-quality monitoring from national water-quality-monitoring authorities, to ensure safe drinking water at the point of use $[8,16]$.

Quantitative Microbial Risk Assessment (QMRA) is a tool to estimate the risk of an adverse effect, such as illness, infection, and/or death from exposure to waterborne, airborne, or foodborne pathogens [17-20]. The QMRA model uses measures of microorganisms in the environment as inputs to calculate associated risks as outputs. QMRA studies can be used to estimate the risk of illness and/or infection due to the exposures from various doses of waterborne pathogens [21-23]. QMRA has been widely used for microbial risk assessment from water (natural recreational water, wastewater treatment plants, rivers, seawater, and wastewater) and food sources, in both community and occupational settings $[17,18,20-22]$. To the best of our knowledge, this is first of study to estimate the risks posed by microbial contamination in drinking water, in school settings.

The specific objectives of this study include the characterization of water-supply conditions in primary schools in Sindh, Pakistan, and the application of QMRA to estimate the risk of infections in children attending those schools. These findings will help policymakers to develop water-safety plans.

\section{Materials and Methods}

\subsection{Study Area (Sindh)}

Pakistan is administratively divided into four provinces. Sindh province is the second largest province, with a population of around 4.8 million, and is located in the southeast of the country. Sindh province has three climatic regions (units), north, south, and central, and each region is subdivided into districts. Sindh has 29 districts. The main source of drinking water in Central Sindh is groundwater; 
in North Sindh, it is groundwater and surface water; and South Sindh mainly depends on surface water (Figure 1). The districts in South Sindh, especially Karachi and Sujawal, are near the sea, therefore, groundwater is too salty and cannot be utilized for drinking water purposes without treatment, so surface water is the main source of drinking water in these both districts [15,24]. A thorough water, sanitation, and hygiene (WASH) survey, along with microbial water-quality analysis, was carried out in all the selected schools.

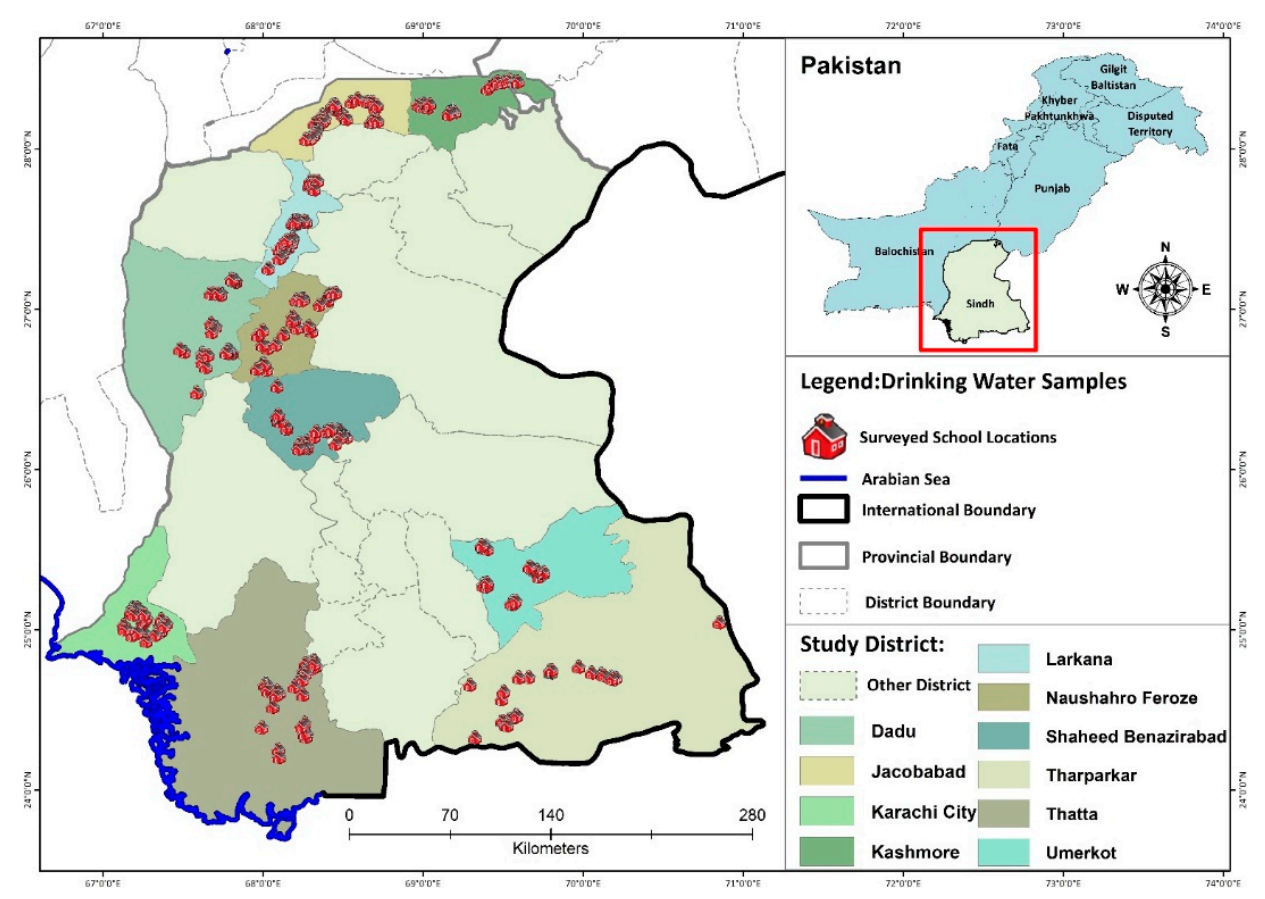

Figure 1. Surveyed school locations in different districts of Sindh.

\subsection{Sampling}

A total of 42,900 schools are registered with the Government Education Department of Sindh [25], and a sample size of 425 schools was selected, using multistage random-sampling techniques. The sampling scheme produces a random sample, representative of the whole of Sindh province (Table 1). In the first phase, 10 districts were randomly selected, with a probability of selection proportionate to size, and then in the second stage, primary schools were randomly sampled from each district, to accomplish drinking-water sampling from 425 schools. All water samples were taken in the same season, between November and January. The schools were assessed using the WHO standard WASH assessment tool [26]. The headmaster of each school was interviewed, and drinking-water samples and structured observations of WASH were collected. ODK Collect Android Software was used to collect survey data [27]. Structured observations of water facilities were carried out, to assess the availability, accessibility, and functionality of water facilities. The questionnaire was translated into both English and Sindhi (local language), to ensure ease of use. The survey was pre-tested among six schools, to evaluate clarity of the translated questions, the appropriateness of the wordings based on the cultural and belief, and the duration of time taken to answer the questionnaire. 
Table 1. Details about the sampled districts, schools, and sources of the water samples.

\begin{tabular}{cccc}
\hline Location & Districts & N Primary Schools & Sources of Drinking Water \\
\hline \multirow{3}{*}{ North Sindh } & Larkana & 42 & Ground (88\%), Surface (12\%) \\
& Jacobabad & 40 & Ground (67\%), Surface (33\%) \\
& Kashmore & 42 & Ground (83\%), Surface (16\%) \\
\hline \multirow{3}{*}{ Central Sindh } & S. Benazirabad & 47 & Ground (87\%), Surface (13\%) \\
& Dadu & 42 & Ground (83\%), Surface (17) \\
& Naushahro Feroze & 45 & Ground (94\%), Surface (6\%) \\
\hline \multirow{3}{*}{ South Sindh } & Tharparkar & 42 & Surface (55\%), Ground (45\%) \\
& Sujawal & 40 & Surface (85\%), Ground (15\%) \\
& Karachi & 40 & Surface (98\%) Ground (2\%) \\
& Umerkot & 45 & Ground (58\%), Surface (42\%) \\
\hline
\end{tabular}

\subsection{Microbial Contamination of Drinking-Water Sources}

Microbial risk assessment was carried out. We first collected drinking-water samples from selected primary schools. The most commonly found bacteria, including Escherichia coli, Salmonella spp., Vibrio cholerae, and Shigella spp., were considered for QMRA tool [28,29]. QMRA involves estimating the risk of infection or illness due to exposure to pathogenic microorganisms [28]. It consists of (1) hazard identification, (2) dose-response assessment, (3) exposure assessment, and (4) risk characterization [28]. Our primary data include identification of E. coli, Salmonella spp., V. cholerae, and Shigella spp. E. coli is considered an indicator organism and is used in the present study, to estimate the risk of two other commonly reported pathogenic contaminants, i.e., Campylobacter and Rotavirus, in the drinking-water sources [29-31]. The data regarding exposed population, frequency of water consumption ( $\mathrm{V}=1$ Liter per day for children), and exposure pathways were estimated from previous studies [29,30].

\subsection{Hazard Identification}

Measures of E. coli, Salmonella spp., Shigella spp., and V. cholerae were used to directly estimate students' exposures to bacterial contaminants through drinking water available in primary schools. Furthermore, Campylobacter and Rotavirus were estimated on the basis of indicator organism. Pathogenic strains of E. coli are major hazards for public health [30]. The literature revealed that the $8 \%$ of the total E. coli is pathogenic, so the E. coli dose was multiplied by 0.08 , in order to estimate the dose of pathogenic E. coli, as has been done elsewhere [28,29]. Campylobacter and Rotavirus were also predicted, using the E. coli to pathogenic ratio $[19,29]$. From each school's drinking-water source at the point of use, $1500 \mathrm{~mL}$ of drinking water was collected in a sterile bag. The collected sample was preserved in an ice box, at a temperature of approximately $4{ }^{\circ} \mathrm{C}$, and then the samples were transported to the ISO certified national laboratory, for the detection of selected pathogenic bacteria from drinking-water samples.

\subsection{Isolation and Identification of Bacteria in Drinking Water}

The membrane filtration method and selective agar media were used for the detection of E. coli (TBX agar Sigma), V. cholerae (Cholera Medium TCBS Oxoid England), Shigella, and Salmonella spp. (X.L.D. Agar Oxoid England). The standard membrane-filtration method was used for the detection of E. coli, V. cholerae, Shigella, and Salmonella spp. Every bacterium isolated separately, using $100 \mathrm{~mL}$ water samples, was filtered through membrane filtration, and the filter was placed on the selective agar plates, for incubation, for 22 to $24 \mathrm{~h}$. After incubation, the number of colonies was counted on selective agars plates and reported in colony-forming unit (CFU/100 mL); all the samples were analyzed in replicate, and results were recorded in average, using standard drinking-water testing techniques [29]. 


\subsection{Dose-Response Assessment}

The dose-response (DR) assessment characterizes the relationship between the number of pathogens ingested (dose) and the likelihood of occurrence of an adverse consequence, in terms of infection, illness, or death. A $\beta$-Poisson dose-response model is shown in Equation (1): [28]

$$
\frac{\operatorname{Pinf}}{\text { day }}=1-\left[1+\left(\frac{d}{N 50}\right)\left(2^{\frac{1}{\propto}}-1\right)\right]
$$

where $\mathrm{d}$ is the dose, N50 is the dose corresponding to the median response, and alpha is a parameter of the distribution. Our models' parameter assumptions are shown in Table 2.

Table 2. Dose-response parameters.

\begin{tabular}{|c|c|c|c|}
\hline Organisms & Parameters & Type of Model & Reference \\
\hline Escherichia coli & $\begin{array}{l}\alpha=0.2099 \\
N 50=1120 \\
P D i=0.35\end{array}$ & $\beta$-Poisson model & {$[28-30,32]$} \\
\hline Campylobacter * & $\begin{array}{l}\alpha=0.145 \\
\text { N50 }=896 \\
\text { PDi }=0.7\end{array}$ & $\beta$-Poisson model & {$[29,32]$} \\
\hline Rotavirus * & $\begin{array}{l}\alpha=0.2531 \\
\text { N50 }=6.17 \\
\text { PDi }=0.5\end{array}$ & $\beta$-Poisson model & {$[28,29]$} \\
\hline Salmonella spp. & $\begin{array}{l}\alpha=0.21 \\
\beta^{* *}=49.78 \\
\text { N50 }=1.11 \times 10^{6} \\
\text { PDi }=0.45\end{array}$ & $\beta$-Poisson model & [33] \\
\hline Shigella spp. & $\begin{array}{l}\alpha=0.265 \\
\beta^{* *}=1480 \\
\mathrm{PDi}=0.35\end{array}$ & $\beta$-Poisson model & [33] \\
\hline Vibrio cholerae & $\begin{array}{l}\alpha=0.250 \\
\beta^{* *}=243 \\
\mathrm{PDi}=0.2\end{array}$ & $\beta$-Poisson model & [33] \\
\hline
\end{tabular}

* Predicted based on assumptions from the literature, using total measured E. coli. ${ }^{* *} \mathrm{~N} 50$ can be reparametrized in terms of $\beta[29]$.

\subsection{Exposure through Drinking-Water Sources}

The average number of days per year when water was consumed from a source was 300 days; the remaining days were vacations and/or public holidays. The consumed volumes was 1 liter per day per child, and they were estimated as done in previous studies $[29,30]$ and based on our survey data.

\subsection{Risk Characterization}

For risk characterization, the probability of annual infection and probability of illness are determined by using a standard equation [20]. The annual probability of infection is calculated via Equation (2):

$$
\text { Pinf annual }=1-[1-\operatorname{Pinf} / \text { day }]^{\mathrm{n}}
$$

where the probability infection per day (Pinf/day) was obtained from Equation (1), above, and $\mathrm{n}$ is the number of exposure days in a year. The probability of illness was calculated by Equation (3):

$$
\text { Pill }=\text { P infannual } \times \text { Pill } / \text { inf }
$$

where Pill/inf is the probability of illness per infection, and P inf annual is defined in Equation (2). 


\section{Results}

\subsection{Characterization of Water Samples}

Drinking-water samples from the point of use were collected in all 425 primary schools. As described earlier, the most common sources of drinking water were groundwater in Central Sindh, groundwater and surface water in North Sindh, and surface water in South Sindh (Table 1). The sources of water at school were mainly groundwater or dug-well (62\%) and surface water supplied through pipes and water cans/plastic bottles (38\%). Year-round availability of water from the main source was reported by one-third of schools (33.4\%). Onsite water-treatment systems were available at $20.2 \%$ of the schools, in which filtration was used as the main method (commercial filters, including carbon, limestone, and fiber thread), followed by boiling, chlorination, and ultraviolet disinfection. None of the schools had tested the drinking water's quality during the past two years.

Other data we collected indicated that only one-third of the schools, mainly private schools, had water-storage capacity, such as an overhead or underground tank. None of these tanks had been cleaned in the past six months. Using the United Nations' (UN) joint monitoring program (JMP) WASH's definitions for schools [34], water-service levels at these selected schools were assessed, and 7\% of schools had advanced service levels, $57.4 \%$ had basic, $19.8 \%$ had limited, and $16 \%$ of schools had no service at all.

\subsection{Microbial Quality of Drinking Water}

Our study showed that, across all schools, $49 \%$ of the drinking-water samples were contaminated with E. coli, 54\% with Salmonella spp., 49\% with V. cholerae, and 63\% were contaminated with Shigella (Table 3). E. coli contamination in drinking water was highest in the Karachi district, followed by S. Benazirabad and Umerkot. Salmonella spp. contamination was higher in Larkana, Naushahro Feroze, and Umerkot than the other districts. Additionally, water samples from Naushahro Feroze exhibited more $V$. cholerae contamination than the other districts.

Table 3. Frequency of microbial contamination.

\begin{tabular}{cccccc}
\hline \multirow{2}{*}{ Districts } & \multirow{2}{*}{ N Schools } & \multicolumn{4}{c}{ \% with Contaminated Water Sources } \\
\cline { 3 - 6 } & & E. Coli & Salmonellae spp. & V. Cholerae & Shigella \\
\hline Dadu & 42 & 50.0 & 47.6 & 31.0 & 54.8 \\
Jacobabad & 40 & 42.5 & 37.5 & 22.5 & 67.5 \\
Karachi & 40 & 60.0 & 42.5 & 27.5 & 90.0 \\
Larkana & 42 & 21.4 & 69.0 & 57.1 & 45.2 \\
S. Benazirabad & 47 & 57.4 & 55.3 & 55.3 & 76.6 \\
Sujawal & 40 & 57.5 & 47.5 & 30.0 & 57.5 \\
Tharparkar & 42 & 23.8 & 57.1 & 59.5 & 52.4 \\
Naushahro & 45 & 64.4 & 64.4 & 93.3 & 82.2 \\
Feroze & 45 & 68.9 & 64.4 & 60.0 & 55.6 \\
Umerkot & 42 & 45.2 & 50.0 & 57.1 & 52.4 \\
Kashmore & 425 & 49.4 & 53.9 & 50.1 & 63.5 \\
\hline Overall & 425
\end{tabular}

Water contamination was worse in South Sindh, where surface water is an important source of drinking water. Water was highly contaminated with E. coli (Umerkot 68.9\%, Karachi 60\%, and Sujawal $57.5 \%)$. There was also a high prevalence of Salmonella spp. in the drinking-water samples of Larkana (69\%), Umerkot (64.4\%), and N. Feroze (64.4\%). The prevalence of Salmonella spp. was comparatively lower in Northern Sindh (Kashmore 50.1\% and Jacobabad 47.5\%). Vibrio cholerae contamination was higher in the drinking-water samples of Central Sindh (N. Feroze 93.3\%, Umerkot 60\%) and lower in the Northern Sindh (Dadu 31\% and Jacobabad 22.5\%). Overall, our study revealed that the there is a high prevalence of $V$. cholerae and Shigella in the drinking-water samples. The prevalence of Shigella 
(Table 3) was highest in the southern districts of Sindh (Karachi 90\% and N. Feroze 82.2\%) and lowest in the northern districts (Larkana 45.2\%, Dadu 54.8\%, and Kashmore 52.4\%; Table 3).

The average number of bacteria ingested was calculated; the highest ingestion doses per day were for V. cholerae, followed by Shigella and then Campylobacter (Table 4). The number of E. coli ingested per day was the highest in Jacobabad and Karachi and was the lowest in the Kashmore and Larkana districts. Shigella ingestion was the highest in the central region of Sindh (Naushahro Feroze, Dadu) and the lowest in S. Benazirabad.

Table 4. Average bacterial ingestion by children.

\begin{tabular}{|c|c|c|c|c|c|c|}
\hline \multirow{2}{*}{ Districts } & \multicolumn{6}{|c|}{ Average Bacterial Ingestion Colony Forming Unit (CFU)/Day } \\
\hline & E. Coli & Salmonella spp. & V. Cholerae & Shigella & Campylobacter & Rotavirus \\
\hline Dadu & $0.8476 \times 10^{1}$ & $2.381 \times 10^{1}$ & $1.3095 \times 10^{1}$ & $8.2619 \times 10^{1}$ & $6.9928 \times 10^{1}$ & $10.5 \times 10^{-4}$ \\
\hline Jacobabad & $0.4375 \times 10^{1}$ & $4.025 \times 10^{1}$ & $0.925 \times 10^{1}$ & $1.3475 \times 10^{2}$ & $3.6135 \times 10^{1}$ & $54.7 \times 10^{-5}$ \\
\hline Karachi & $2.916 \times 10^{1}$ & $5.4 \times 10^{1}$ & $2.425 \times 10^{1}$ & $2.49 .5 \times 10^{2}$ & $2.405 \times 10^{2}$ & $36.01 \times 10^{-4}$ \\
\hline Larkana & $0.295 \times 10^{1}$ & $5.9286 \times 10^{1}$ & $2.7143 \times 10^{1}$ & $3.7381 \times 10^{1}$ & $2.4357 \times 10^{1}$ & $36.9 \times 10^{-5}$ \\
\hline S. Benazirabad & $0.925 \times 10^{1}$ & $5.9167 \times 10^{1}$ & $3.8125 \times 10^{1}$ & $1.01667 \times 10^{2}$ & $7.631 \times 10^{1}$ & $11.56 \times 10^{-4}$ \\
\hline Sujawal & $0.518 \times 10^{1}$ & $5.55 \times 10^{1}$ & $2.0 \times 10^{1}$ & $6.025 \times 10^{1}$ & $4.273 \times 10^{1}$ & $64.7 \times 10^{-5}$ \\
\hline Tharparkar & $0.468 \times 10^{1}$ & $7.8095 \times 10^{1}$ & $7.7857 \times 10^{1}$ & $4.619 \times 10^{1}$ & $3.868 \times 10^{1}$ & $58.5 \times 10^{-5}$ \\
\hline Naushahro Feroze & $1.109 \times 10^{1}$ & $1.89556 \times 10^{2}$ & $1.149556 \times 10^{3}$ & $4.80 \times 10^{2}$ & $9.154 \times 10^{1}$ & $13.8 \times 10^{-5}$ \\
\hline Umerkot & $1.484 \times 10^{1}$ & $8.0889 \times 10^{1}$ & $2.5044 \times 10^{2}$ & $1.9022 \times 10^{2}$ & $1.222 \times 10^{2}$ & $18.5 \times 10^{-4}$ \\
\hline Kashmore & $0.331 \times 10^{1}$ & $1.976 \times 10^{1}$ & $3.6429 \times 10^{1}$ & $3.5238 \times 10^{1}$ & $2.734 \times 10^{1}$ & $41.4 \times 10^{-5}$ \\
\hline
\end{tabular}

Colony Forming Unit $(\mathrm{CFU}) /$ day $=\mathrm{C}^{*} \mathrm{~V} ; \mathrm{C}=$ mean concentration of bacteria; $\mathrm{V}=1$ liter per day for children $[29,30]$. Probability of bacterial ingestion per day based on beta-Poisson dose-response model $[28,30]$. Parameter values listed in Table 2.

We further analyzed the probability of infection to schoolchildren per day and show this by geographic area (Figure 2; Appendix A Table A1). The highest risk due to the E. coli was estimated for the schools located in South Sindh (Karachi 14.9\%), using mainly surface water for drinking purpose, whereas the lowest risk of infection was calculated for the schools of North Sindh, mainly using groundwater. The risk from Salmonella spp. was the highest in Naushahro Feroze (28.1\%), where children were exposed to a mix of surface and groundwater, while the lowest risk of infection was $6.8 \%$ in the Kashmore district. The risk of infection due to the $V$. cholerae was the highest in the schools located in Central Sindh that used a mix of water sources; these included Naushahro Feroze $35 \%$ and Jacobabad $(0.93 \%)$. The risk of infection from Shigella was highest in Naushahro Feroze $(6.9 \%)$ and the lowest in Kashmore $(0.60 \%)$. The daily risk to Rotavirus was very low. The risk due to the Campylobacter was higher in the schools in the south, especially in Karachi, whereas the risk was comparatively low in the northern districts (Figure 2).

We estimated the probability of infection per year for children in primary schools (Table 5). Across all districts, drinking water from primary schools was estimated to lead to an extremely high risk $(>94 \%)$ of infection by each of the bacteria assessed; the probability of infection from Rotavirus was only $23.4 \%$. The risk of illness due to the bacterial infection was also high as compared to the Rotavirus. About $70 \%$ of children were at risk of illness due to Campylobacter, $35 \%$ were at risk of illness due to E. coli, 33\% due to Shigella, $45 \%$ due to Salmonella spp., and $20 \%$ of children were at risk of illness due to $V$. cholerae. The risk of illness due to each of the bacteria had little variation within districts, whereas there was some variation by district for illness by Rotavirus. Schoolchildren in Karachi were estimated to have more risk of Rotavirus-related illness (22.6\%), as compared to children in the Larkana (3\%) and Kashmore (3\%) districts. 

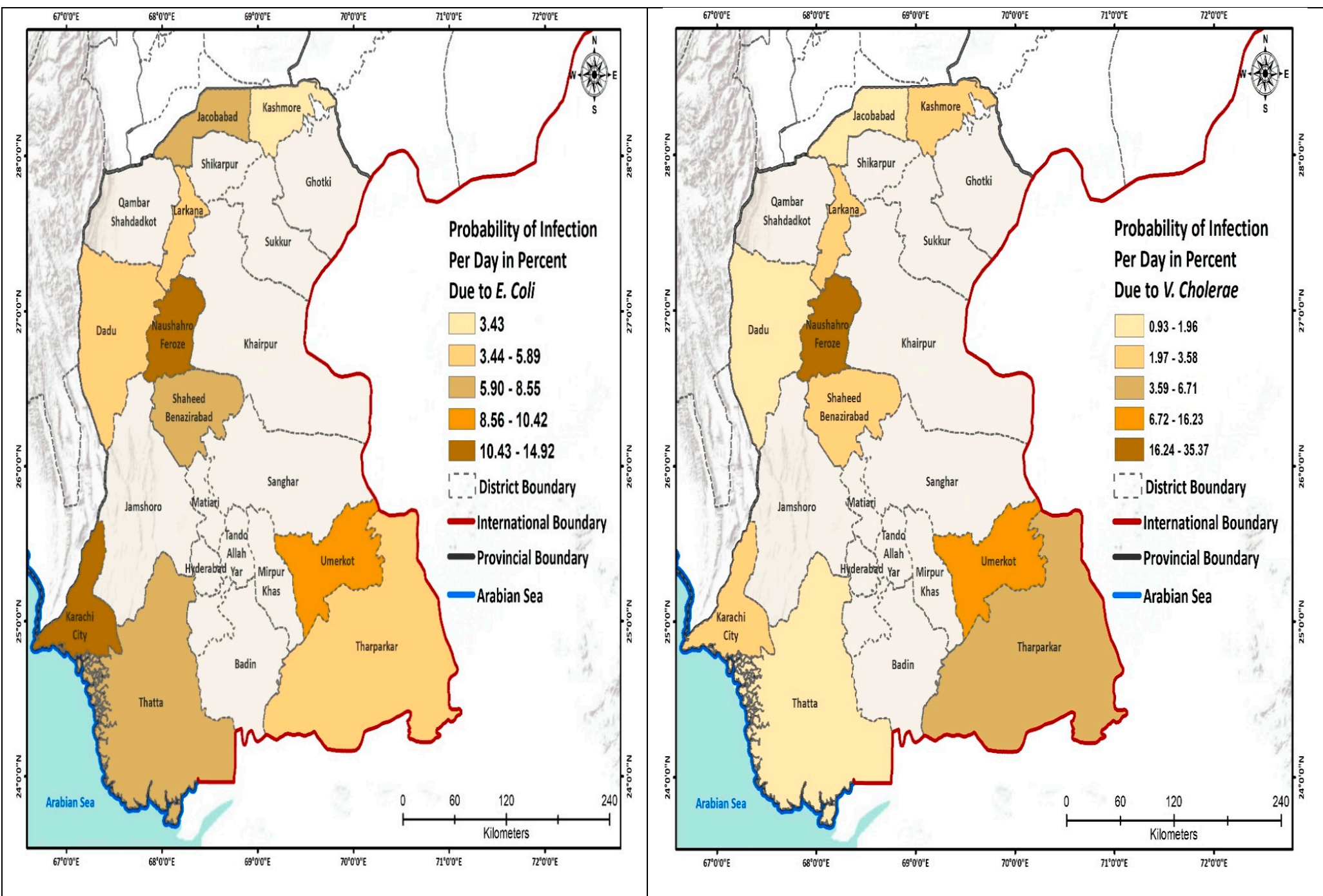

Figure 2. Cont. 


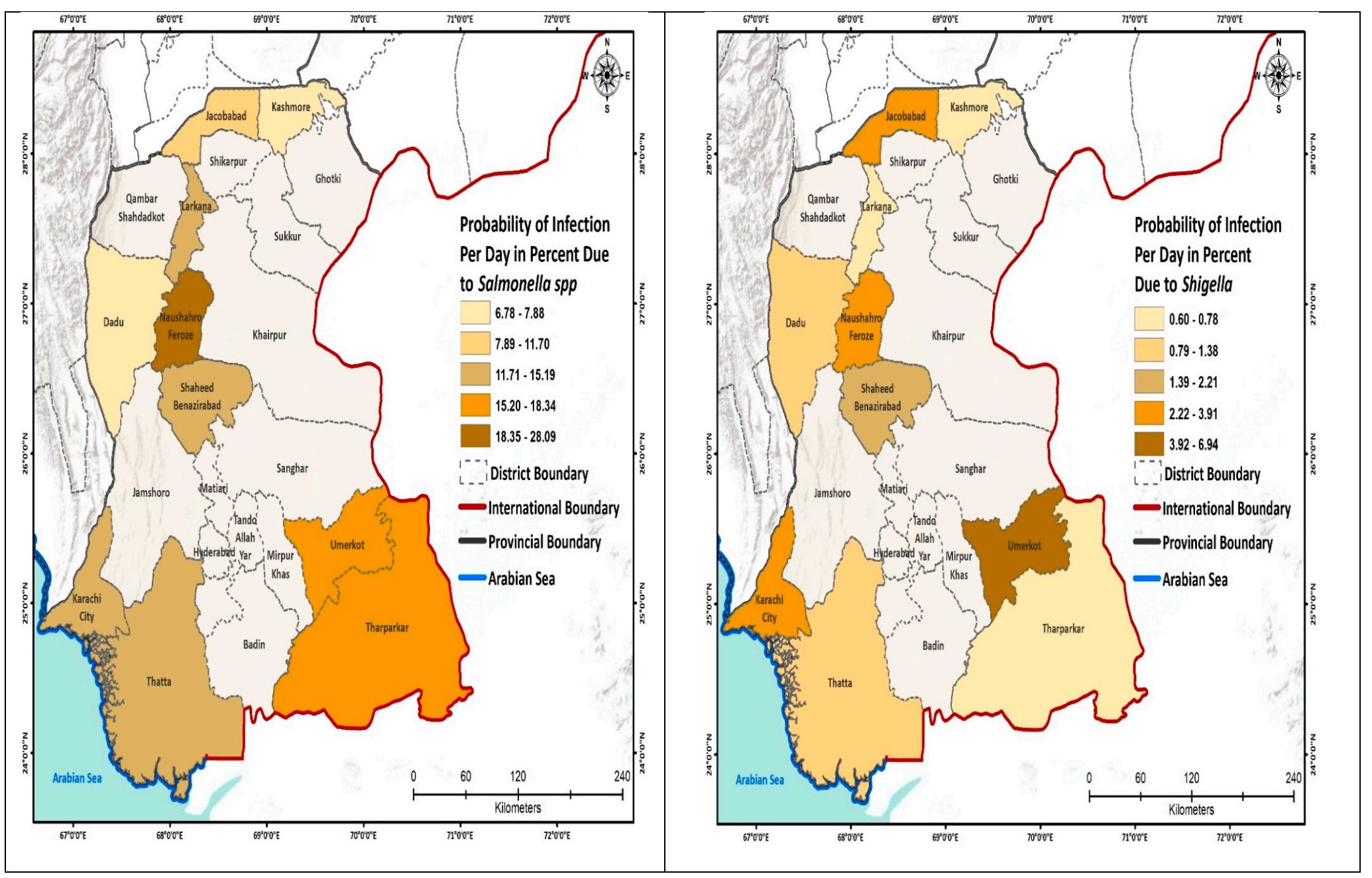

Figure 2. Cont. 


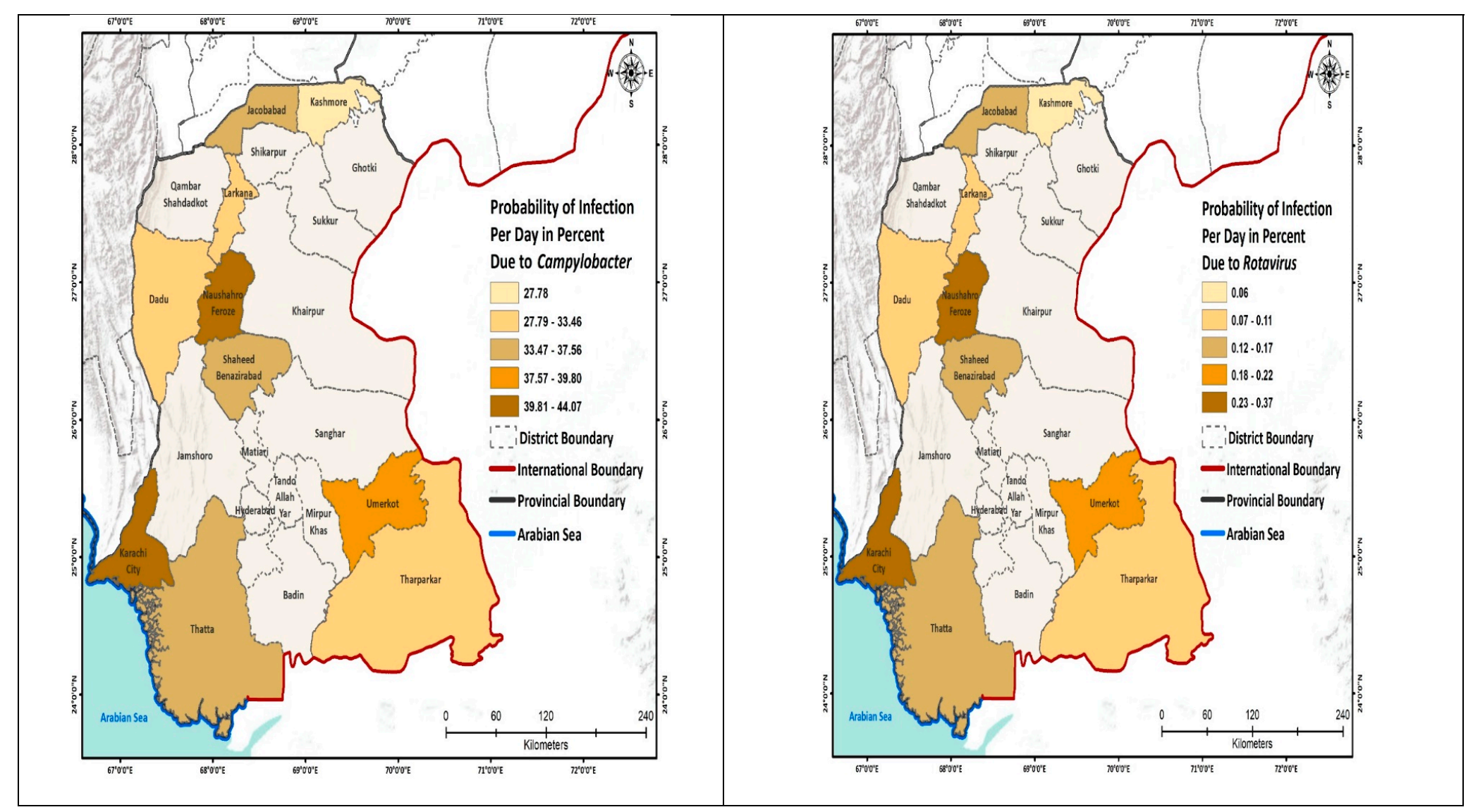

Figure 2. Probability of infection $\left(\mathrm{P}_{\text {inf }}\right)$ to the schoolchildren per day. 
Table 5. Probability of infection per year and probability of illness per year among schoolchildren, due to school drinking-water exposure.

\begin{tabular}{|c|c|c|c|c|c|c|c|c|c|c|c|c|}
\hline \multirow{2}{*}{ District } & \multicolumn{6}{|c|}{ Probability of Infection per Year (\%) } & \multicolumn{6}{|c|}{ Probability of Illness per Year (\%) } \\
\hline & E. Coli & Salmonella spp. & V. Cholerae & Shigella & Campylobacter & Rotavirus & E. Coli & Salmonella spp. & V. Cholerae & Shigella & Campylobacter & Rotavirus \\
\hline Dadu & 100.0 & 100.0 & 97.3 & 97.8 & 100.0 & 1.61 & 35.0 & 45.0 & 19.5 & 34.2 & 70.0 & 8.0 \\
\hline Jacobabad & 99.6 & 100.0 & 92.3 & 99.8 & 100.0 & 8.6 & 34.9 & 45.0 & 18.5 & 34.9 & 70.0 & 4.3 \\
\hline Karachi & 100.0 & 100.0 & 99.9 & 100.0 & 100.0 & 45.1 & 35.0 & 45.0 & 20.0 & 35.0 & 70.0 & 22.6. \\
\hline Larkana & 97.9 & 100.0 & 99.9 & 82.9 & 100.0 & 5.9 & 34.3 & 45.0 & 20.0 & 29.0 & 70.0 & 3.0 \\
\hline S. Benazirabad & 100.0 & 100.0 & 100.0 & 99.1 & 100.0 & 17.4 & 35.0 & 45.0 & 20.0 & 34.7 & 70.0 & 8.7 \\
\hline Sujawal & 99.9 & 100.0 & 99.6 & 94.0 & 100.0 & 10.1 & 35.0 & 45.0 & 19.9 & 32.9 & 70.0 & 5.1 \\
\hline Tharparkar & 99.8 & 100.0 & 100.0 & 88.4 & 100.0 & 92.0 & 34.9 & 45.0 & 20.0 & 31.0 & 70.0 & 4.6 \\
\hline $\begin{array}{l}\text { Naushahro } \\
\text { Feroze }\end{array}$ & 100.0 & 100.0 & 100.0 & 100.0 & 100.0 & 20.5 & 35.0 & 45.0 & 20.0 & 35.0 & 70.0 & 10.2 \\
\hline Umerkot & 100.0 & 100.0 & 100.0 & 100.0 & 100.0 & 26.4 & 35.0 & 45.0 & 20.0 & 35.0 & 70.0 & 13.0 \\
\hline Kashmore & 98.7 & 100.0 & 100.0 & 80.9 & 100.0 & 6.6 & 34.5 & 45.0 & 20.0 & 28.3 & 70.0 & 3.3 \\
\hline Overall & 99.6 & 100.0 & 98.9 & 94.3 & 100.0 & 23.4 & 34.8 & 45.0 & 19.8 & 33.0 & 70.0 & 6.7 \\
\hline
\end{tabular}


The Pearson correlation analysis showed high correlations between various pathogens (Table 6). The strongest associations were between E. coli and Campylobacter; between E. coli and Rotavirus; between V. cholerae and Salmonella; between V. cholerae and Shigella; between Shigella and Salmonella spp.; and between Campylobacter and Rotavirus.

Table 6. Pearson correlation between pathogens.

\begin{tabular}{|c|c|c|c|c|c|c|}
\hline & E. Coli & V. Cholerae & Shigella & Campylobacter & Rotavirus & Salmonella spp. \\
\hline E. coli & 1 & & & & & \\
\hline V. Cholerae & 0.118 & 1 & & & & \\
\hline Shigella & 0.525 & 0.878 * & 1 & & & \\
\hline Campylobacter & $1.000 *$ & 0.118 & 0.525 & 1 & & \\
\hline Rotavirus & 1.000 * & 0.118 & 0.525 & 1.000 * & 1 & \\
\hline Salmonella spp. & 0.156 & $0.942 *$ & $0.833^{* *}$ & 0.156 & 0.156 & 1 \\
\hline
\end{tabular}

* Correlation significant at the 0.01 level (two-tailed).

\section{Discussion}

Our study characterized water, sanitation, and hygiene (WASH) conditions in 425 primary schools of Sindh, Pakistan, and estimated the risk of waterborne infections in schoolchildren. Overall, the risk of illness due to the bacterial infection (E. coli, Salmonella spp., V. cholerae, Shigella, and Campylobacter) was high.

We observed that, on average, almost half (49\%) of the drinking-water samples were contaminated with E. coli, 54\% with Salmonella spp., 49\% with V. cholerae, and 63\% with Shigella. South Sindh mainly depends on surface water for drinking water, and that water appears to be highly contaminated with E. coli (Umerkot $68.9 \%$, Karachi 60\%, and Sujawal 57.5\%). The high risks of infections that we found in the present study are congruent with other available studies of drinking water in Pakistan $[15,24,35]$. The latest Pakistan demographic and health survey in the community settings of the study area reported a high prevalence of waterborne diseases, such as diarrhea, dysentery, cholera, and typhoid [36], which aligns with the high-risk pathogens we found in our study. Recently, a prestigious hospital of the study area has reported the emergence of the first large-scale spread of an extensively drug-resistant (XDR) Salmonella typhi, exhibiting resistance to Trimethoprim-sulfamethoxazole, ampicillin, chloramphenicol, fluoroquinolones, and third-generation cephalosporins [37]. The ongoing outbreak has resulted in more than 300 cases, including 187 pediatric cases since November 2016 [37]. The WHO maintained that the Sindh province of Pakistan is under high risk of acquiring XDR Salmonella spp., because of poor access to clean water, as well as unimproved sanitation and hygiene [38]. In our study, there was a higher prevalence of Salmonella spp. in the drinking-water samples from South and Central Sindh districts, especially in Umerkot (64.4\%) and N. Feroze (64.4\%). The prevalence of Salmonella spp. was comparatively lower in Northern Sindh (Kashmore 50\% and Jacobabad 37\%).

The global burden of $V$. cholerae and Shigella is mostly unidentified, because the majority of the cases go unreported $[7,10]$. Poor reporting can be ascribed to economic, social, and political disincentives for reporting, as well as the inadequate capacity of laboratories and epidemiological surveillance in schools of low resource countries [39-41]. In our study, V. cholerae contamination was higher in the drinking-water samples of Central Sindh, and lower in the Northern Sindh. Almost half of the schools in the study area possess unimproved sanitation system [9]. Poor sanitation poses frequent risks of cholera and shigellosis [42]. Our study findings also revealed a high prevalence of $V$. cholerae and Shigella pathogens in the analyzed drinking-water sources. Shigella prevalence was highest in the southern districts of Sindh and lowest in the northern districts.

School-going children in Karachi were estimated to have a higher risk of Rotavirus-related illness $(22.6 \%)$ than children in the N. Feroze district $(10.2 \%)$ and lowest in Umerkot and Larkana districts $(3 \%)$, where groundwater was the primary source of drinking water. Several studies in the region have attributed Rotavirus as an important cause of illness in children. A study in a tertiary-level hospital 
in Sindh Pakistan found Rotavirus among 63\% of children presenting with diarrhea [43]. The Indian subcontinent (Pakistan, Bangladesh, and India) attributes three-fourths of the deaths to Rotavirus, which is considered the most common cause of severe diarrhea among young children [44].

Waterborne Campylobacter infections are associated with recurrent diarrhea in children, which ultimately affect children's school performance [45]. In our study, the risk of Campylobacter infection was higher among the schoolchildren in the south and lower in children studying in the northern region. The south region is located at the tail end of the Indus River, where surface water is the main source of drinking water. The waterborne diseases among children in that region are reported quite high $[7,15]$. There can be multiple reasons for source-water contamination, including mixing up of industrial or household waste into the surface water without treatment. Additionally, a poorly functioning water-treatment system could also be a problem. Non-separation of waste and water supply line result in contamination of the water-system network [29]. The delivery of improved water at schools can contribute to the improved health and educational performance. Further, water helps to maintain environmental and personal hygiene, decrease chances of dehydration at schools, and ultimately contribute to improved cognitive abilities [27,46].

The geographical differences in pathogen-related health risks between North and South Sindh were likely due to different types of water sources. Across all sites, generally schools that used surface water had a higher risk of infection. This is similar to many other studies that have found the highest burden of waterborne diseases in a low-income population, using surface water as a main source of drinking [47].

Surface water in places with poor infrastructure can create exposure to contamination through open drainage channels, unprotected tertiary drains, and contaminated soil [47,48]. Diseases related to inadequate water, sanitation, and hygiene carries a huge burden of disease in low-income countries. Schools situated in rural settings often lack drinking-water, sanitation, and hand-washing facilities; even where such facilities exist, they are often inadequate in both quantity and quality. Schools deprived of improved water sanitation and hygiene conditions pose a high risk of disease transmission by intense levels of person-to-person contact [34,49].

There were several limitations in our study. Firstly, students might not be drinking from the school water sources, but instead drink from their personal water bottles, brought from home. Secondly, we only studied six pathogens, based on our limited resources; however, there are other waterborne pathogens which may be considered in future studies. Further, our estimates of pathogenic E. coli, of Campylobacter, and of Rotavirus were based on predicted doses, using assumptions from the literature and using our measure of total E. coli. Thirdly, our results have not taken into consideration the uncertainty of the risk of our estimates (e.g., like Monte-Carlo analysis would do). Finally, we only collected a single sample of water from each school, whereas water quality may vary seasonally.

\section{Conclusions}

QMRA is a useful tool that is widely used in community settings, to predict the probability of infection and illness in large populations due to exposure to microbiologically unsafe water. This is the first study conducted in school settings that used the QMRA tool to estimate the risks of waterborne diseases through drinking-water sources. The study findings revealed that drinking water in each region presents varying degrees of health risk. Our QMRA results will help to inform the water-quality situation, health-risk poses to the study population, and dire need for management plans in schools of Sindh. Improved access to safe water and sanitation are critical to halt the progression of waterborne diseases. For improving drinking-water quality, we recommend periodic water-quality monitoring and, where necessary, the use of simple, low-cost, and sustainable drinking-water treatment methods, such as boiling, solar disinfection, and chlorination. 
Author Contributions: Designed study, J.A., J.V.G, L.P.W., Y.P.C., and J.A.V.; field work, J.A., N.C., and A.Y.; analyzed data, J.A., N.C., R.B.M., L.P.W., and Y.P.C.; wrote the manuscript, J.A., L.P.W., Y.P.C., and J.V.G. All authors have read and agreed to the published version of the manuscript.

Funding: This study was funded by USAID (USPCASW/P-II/07 Seed Grant).

Acknowledgments: The researchers want to acknowledge USAID for providing financial support (under USPCASW seed grant Phase-II); School of Community Health Sciences at the University of Nevada, Reno and Division of Public Health at the University of Utah for providing technical support and US-Pakistan Center for Advance Studies in Water, Mehran University of Engineering and Technology for providing the platform to accomplish this research project.

Conflicts of Interest: The authors declare no conflict of interest.

\section{Appendix A}

Table A1. Probability of infection per day (Pinf).

\begin{tabular}{ccccccc}
\hline $\begin{array}{c}\text { Districts of Sindh } \\
\text { Selected for } \\
\text { This Study }\end{array}$ & $\begin{array}{c}\mathbf{P}_{\text {inf }} E . \\
\text { Coli/Day }\end{array}$ & $\begin{array}{c}\mathbf{P}_{\text {inf }} S . \\
\text { Typhi/Day }\end{array}$ & $\begin{array}{c}\mathbf{P}_{\text {inf }} \boldsymbol{V} . \\
\text { Cholera }\end{array}$ & $\mathbf{P}_{\text {inf }}$ Shigella & $\begin{array}{c}\mathbf{P}_{\text {inf }} \\
\text { Campylobacter }\end{array}$ & $\begin{array}{c}\mathbf{P}_{\text {inf }} \\
\text { Rotavirus }\end{array}$ \\
\hline Dadu & 0.0372 & 0.0788 & 0.013 & 0.0138 & 0.2861 & $3.2 \times 10^{-4}$ \\
\hline Jacobabad & 0.0202 & 0.117 & 0.0093 & 0.0221 & 0.2243 & $1.6 \times 10^{-4}$ \\
\hline Karachi & 0.1033 & 0.143 & 0.0235 & 0.0391 & 0.3969 & $10.9 \times 10^{-4}$ \\
\hline Larkana & 0.0139 & 0.1519 & 0.0261 & 0.0064 & 0.1881 & $1.1 \times 10^{-4}$ \\
\hline Nawabshah & 0.0402 & 0.1517 & 0.0358 & 0.0169 & 0.2942 & $3.5 \times 10^{-4}$ \\
\hline Sujawal & 0.0236 & 0.1455 & 0.0196 & 0.0102 & 0.2399 & $1.9 \times 10^{-4}$ \\
\hline Tharparkar & 0.0215 & 0.1797 & 0.0671 & 0.0078 & 0.2305 & $1.8 \times 10^{-4}$ \\
\hline Noushehro Feroze & 0.0472 & 0.2809 & 0.3537 & 0.0694 & 0.3111 & $6.9 \times 10^{-4}$ \\
\hline Umerkot & 0.0605 & 0.1834 & 0.1623 & 0.0305 & 0.3377 & $5.6 \times 10^{-4}$ \\
\hline Kashmore & 0.0155 & 0.0678 & 0.0343 & 0.006 & 0.1986 & $1.2 \times 10^{-4}$ \\
\hline
\end{tabular}

\section{References}

1. WHO. Annual Report WHO/UNICEF Joint Monitoring Programme (JMP) for Water Supply and Sanitation; WHO: Geneva, Switzerland, 2018.

2. Sauer, M.; Smith, S.; Clemens, B. Does it Pay to Invest in Potable Water in the Developing World? Relationships Between External Financing and Economic Development in Sustainable Community-Run Integrated Projects. J. Int. Dev. 2016, 28, 233-242. [CrossRef]

3. Cairncross, S.; Feachem, R. Environmental Health Engineering in the Tropics: Water, Sanitation and Disease Control; Routledge: Abington, UK, 2018.

4. Nawaz, S.; Ali, Y. Factors affecting the performance of water treatment plants in Pakistan. Water Conserv. Sci. Eng. 2018, 3, 191-203. [CrossRef]

5. JMP. Progress on Drinking Water, Sanitation and Hygiene: 2017 Update and SDG Baselines; World Health Organization: Geneva, Switzerland, 2017.

6. UNICEF. Child Survival Fact Sheet: Water and Sanitation; UNICEF: New York, NY, USA, 2018.

7. Rahman, A.E.; Moinuddin, M.; Molla, M.; Worku, A.; Hurt, L.; Kirkwood, B.; Mohan, S.B.; Mazumder, S.; Bhutta, Z.; Raza, F. Childhood diarrhoeal deaths in seven low-and middle-income countries. Bull. World Health Organ. 2014, 92, 664-671. [CrossRef] [PubMed]

8. Ahmed, T.; Pervez, A.; Mehtab, M.; Sherwani, S.K. Assessment of drinking water quality and its potential health impacts in academic institutions of Abbottabad (Pakistan). Desalin. Water Treat. 2015, 54, 1819-1828. [CrossRef]

9. UNICEF. Water, Sanitation and Hygiene (WASH) in Public Sector Schools Strategic Plan for Sindh; UNICEF: New York, NY, USA, 2016; pp. 3-524.

10. Zahid, J. Impact of Clean Drinking Water and Sanitation on Water Borne Diseases in Pakistan; Sustainable Development Policy Institute: Islamabad, Pakistan, 2018. 
11. WaterAid. The Water Gap-The State of the World's Water 2018; WaterAid: London, UK, 2018.

12. Amin, R.; Zaidi, M.B.; Bashir, S.; Khanani, R.; Nawaz, R.; Ali, S.; Khan, S. Microbial contamination levels in the drinking water and associated health risk in Karachi, Pakistan. J. Water Sanit. Hyg. Dev. 2019, 9, 319-328. [CrossRef]

13. Azizullah, A.; Khattak, M.N.K.; Richter, P.; Häder, D.-P. Water pollution in Pakistan and its impact on public health-A review. Environ. Int. 2011, 37, 479-497. [CrossRef]

14. Bosan, A.; Qureshi, H.; Bile, K.M.; Ahmad, I.; Hafiz, R. A review of hepatitis viral infections in Pakistan. JPMA J. Pak. Med. Assoc. 2010, 60, 1045.

15. Daud, M.; Nafees, M.; Ali, S.; Rizwan, M.; Bajwa, R.A.; Shakoor, M.B.; Arshad, M.U.; Chatha, S.A.S.; Deeba, F.; Murad, W. Drinking water quality status and contamination in Pakistan. BioMed. Res. Int. 2017, 2017, 7908183. [CrossRef]

16. Rind, A.; Mastoi, A.; Mastoi, G.; Almani, K.; Hullio, A.; Somroo, A.; Mallah, S. Quality examination of drinking water: A cause study of water filtration plants installed at Hyderabad city, Sindh, Pakistan. J. Biodivers. Environ. Sci. 2014, 4, 289-295.

17. Carducci, A.; Donzelli, G.; Cioni, L.; Federigi, I.; Lombardi, R.; Verani, M. Quantitative microbial risk assessment for workers exposed to bioaerosol in wastewater treatment plants aimed at the choice and setup of safety measures. Int. J. Environ. Res. Public Health 2018, 15, 1490. [CrossRef]

18. Carducci, A.; Donzelli, G.; Cioni, L.; Verani, M. Quantitative microbial risk assessment in occupational settings applied to the airborne human adenovirus infection. Int. J. Environ. Res. Public Health 2016, 13, 733. [CrossRef] [PubMed]

19. Owens, C.E.; Angles, M.L.; Cox, P.T.; Byleveld, P.M.; Osborne, N.J.; Rahman, M.B. Implementation of quantitative microbial risk assessment (QMRA) for public drinking water supplies: Systematic review. Water Res. 2020, 174, 115614. [CrossRef] [PubMed]

20. Kundu, A.; Wuertz, S.; Smith, W.A. Quantitative microbial risk assessment to estimate the risk of diarrheal diseases from fresh produce consumption in India. Food Microbiol. 2018, 75, 95-102. [CrossRef] [PubMed]

21. Federigi, I.; Verani, M.; Donzelli, G.; Cioni, L.; Carducci, A. The application of quantitative microbial risk assessment to natural recreational waters: A review. Mar. Pollut. Bull. 2019, 144, 334-350. [CrossRef] [PubMed]

22. Verani, M.; Federigi, I.; Donzelli, G.; Cioni, L.; Carducci, A. Human adenoviruses as waterborne index pathogens and their use for Quantitative Microbial Risk Assessment. Sci. Total Environ. 2019, 651, 1469-1475. [CrossRef] [PubMed]

23. Rasheduzzaman, M.; Singh, R.; Haas, C.N.; Tolofari, D.; Yassaghi, H.; Hamilton, K.A.; Yang, Z.; Gurian, P.L. Reverse QMRA as a Decision Support Tool: Setting Acceptable Concentration Limits for Pseudomonas aeruginosa and Naegleria fowleri. Water Conserv. Sci. Eng. 2019, 11, 1850. [CrossRef]

24. Memon, M.; Soomro, M.S.; Akhtar, M.S.; Memon, K.S. Drinking water quality assessment in Southern Sindh (Pakistan). Environ. Monit. Assess. 2011, 177, 39-50. [CrossRef]

25. Sindh, G.o.; Department, S.E.a.L. Government of Sindh; Pakistan: Sindh, Pakistan, 2019. Available online: http://www.sindheducation.gov.pk./ (accessed on 5 April 2020).

26. Adams, J.; Bartram, J.; Chartier, Y.; Sims, J. Water, Sanitation and Hygiene Standards for Schools in Low-Cost Settings; World Health Organization: Geneva, Switzerland, 2009.

27. Garn, J.V.; Trinies, V.; Toubkiss, J.; Freeman, M.C. The role of adherence on the impact of a school-based water, sanitation, and hygiene intervention in Mali. Am. J. Trop. Med. Hyg. 2017, 96, 984-993. [CrossRef]

28. Haas, C.N.; Rose, J.B.; Gerba, C.P. Quantitative Microbial Risk Assessment; John Wiley \& Sons: Hoboken, NJ, USA, 1999.

29. Machdar, E.; Van Der Steen, N.; Raschid-Sally, L.; Lens, P. Application of quantitative microbial risk assessment to analyze the public health risk from poor drinking water quality in a low income area in Accra, Ghana. Sci. Total Environ. 2013, 449, 134-142. [CrossRef]

30. Howard, G.; Pedley, S.; Tibatemwa, S. Quantitative microbial risk assessment to estimate health risks attributable to water supply: Can the technique be applied in developing countries with limited data? J. Water Health 2006, 4, 49-65. [CrossRef]

31. Mara, D.; Hamilton, A.J.; Sleigh, A.; Karavarsamis, N.; Seidu, R. Tools for risk analysis: Updating the 2006 WHO guidelines. In Wastewater Irrigation and Health; Routledge: Abington, UK, 2009; pp. 115-126. 
32. Westrell, T. Microbial Risk Assessment and Its Implications for Risk Management in Urban Water Systems; Linköping University Electronic Press: Linköping, Switzerland, 2004.

33. Abia, A.L.K.; Ubomba-Jaswa, E.; Genthe, B.; Momba, M.N.B. Quantitative microbial risk assessment (QMRA) shows increased public health risk associated with exposure to river water under conditions of riverbed sediment resuspension. Sci. Total Environ. 2016, 566, 1143-1151. [CrossRef] [PubMed]

34. UNICEF; World Health Organization. Core Questions and Indicators for Monitoring WASH in Schools in the Sustainable Development Goals; WHO: Geneva, Switzerland; UNICEF: New York, NY, USA, 2016.

35. Sarfraz, M.; Sultana, N.; Tariq, M.I. Assessment of groundwater quality and associated health risks in rural areas of sindh (Pakistan). Studia Univ. Babes-Bolyai Chem. 2018, 63. [CrossRef]

36. Studies, N.I.o.P.; Islamabad, P. Pakistan Demographic and Health Survey 2017-18; National Institute of Population Studies (NIPS) [Pakistan]: Islamabad, Pakistan; ICF: Fairfax, VA, USA, January 2019; pp. 1-573.

37. Klemm, E.; Shakoor, S.; Page, A.; Qamar, F.; Judge, K.; Saeed, D.; Wong, V.; Dallman, T.; Nair, S.; Baker, S. Emergence of an extensively drug-resistant Salmonella enterica serovar Typhi clone harboring a promiscuous plasmid encoding resistance to fluoroquinolones and thirdgeneration cephalosporins. mBio 2018, 9, e00105-18. [CrossRef] [PubMed]

38. WHO. Emergencies Preparedness, Response; World Health Organization: Geneva, Switzerland, 2018.

39. Jasper, C.L.T.; Bartram, J. Water and sanitation in schools: A systematic review of the health and educational outcomes. Int. J. Environ. Res. Public Health 2012, 9, 2772-2787. [CrossRef] [PubMed]

40. Pande, G.; Kwesiga, B.; Bwire, G.; Kalyebi, P.; Riolexus, A.; Matovu, J.K.; Makumbi, F.; Mugerwa, S.; Musinguzi, J.; Wanyenze, R.K. Cholera outbreak caused by drinking contaminated water from a lakeshore water-collection site, Kasese District, south-western Uganda, June-July 2015. PLoS ONE 2018, 13, e0198431. [CrossRef]

41. Chanachai, K.; Pittayawonganon, C.; Areechokchai, D.; Suchatsoonthorn, C.; Pokawattana, L.; Jiraphongsa, C. A food borne outbreak of gastroenteritis due to Shigella and possibly Salmonella in a school. Southeast Asian J. Trop. Med. Public Health 2008, 39, 297.

42. Schaetti, C.; Khatib, A.M.; Ali, S.M.; Hutubessy, R.; Chaignat, C.-L.; Weiss, M.G. Social and cultural features of cholera and shigellosis in peri-urban and rural communities of Zanzibar. Infect. Dis. 2010, 10, 339. [CrossRef]

43. Habib, M.I.; Kazi, S.G.; Khan, K.M.A.; Zia, N. Rota virus diarrhea in hospitalized children. J. Coll. Physicians Surg. Pak. 2014, 24, 114.

44. Miles, M.G.; Lewis, K.D.; Kang, G.; Parashar, U.D.; Steele, A.D. A systematic review of rotavirus strain diversity in India, Bangladesh, and Pakistan. Vaccine 2012, 30, A131-A139. [CrossRef]

45. Pitkänen, T. Review of Campylobacter spp. in drinking and environmental waters. J. Microbiol. Methods 2013, 95, 39-47. [CrossRef]

46. Bresee, S.; Caruso, B.; Sales, J.; Lupele, J.; Freeman, M. 'A child is also a teacher': Exploring the potential for children as change agents in the context of a school-based WASH intervention in rural Eastern Zambia. Health Educ. Res. 2016, 31, 521-534. [CrossRef] [PubMed]

47. Katukiza, A.; Ronteltap, M.; Van Der Steen, P.; Foppen, J.; Lens, P. Quantification of microbial risks to human health caused by waterborne viruses and bacteria in an urban slum. J. Appl. Microbiol. 2014, 116, 447-463. [CrossRef] [PubMed]

48. Gadgil, A. Drinking water in developing countries. Annu. Rev. Energy environ. 1998, 23, 253-286. [CrossRef]

49. Siddiqui, N.; Gorard, S. Comparing government and private schools in Pakistan: The way forward for universal education. Int. J. Educ. Res. 2017, 82, 159-169. [CrossRef]

(C) 2020 by the authors. Licensee MDPI, Basel, Switzerland. This article is an open access article distributed under the terms and conditions of the Creative Commons Attribution (CC BY) license (http://creativecommons.org/licenses/by/4.0/). 